\title{
Urban Engineering 2.0 - Medial Construction of Regional and Local Identification with RegioWikis and CityBlogs
}

\author{
Stefan Selke \\ Furtwangen University \\ ses@hs-furtwangen.de \\ Germany
}

\section{Introduction: Local Identity in the Network Society}

No less a person than Manuel Castells, author of the trilogy "The Information Age" (Castells, 2002) has concerned himself with the connection between digital media and the planning of urban living spaces, from the viewpoint both of a media sociologist and of a urban and regional planner. It is also from him that we have the far-reaching term the "information network society". This new term referring to society is not a new appearance without precursors. Instead, it is based on the preceding concepts of the "knowledge society" (Drucker, 1999) and the "post-industrial society" (Bell, 1979). In the network society new challenges are brought before the members of a society. The accumulation of knowledge reaches its highest level of complexity here. The building of networks is a new societal paradigm that can be recognized not only in technical networks but also in social and geographical ones. When there are no longer constraints of space and time, new network-based communities of interest arise. The constant adjustment activities of the "flexible man" (Sennet, 2000) associated with this result in ever more problems in the network society. In tradition-deprived societies we suffer from "need for identity" and see ourselves turning to "self-crafted existence" (Hitzler \& Honer, 1989). One item of this identity kit is local identity, that is always becoming more fleeting and increasingly uses new network media for its formation - according to the premise of this work.

If we understand "societation" (Vergesellschaftung) to be the continuing process of communicative production and reproduction of social relationships, a fundamental change is clear. Whereas locality-related communication was previously used in determining one's place in society, this is for many people rather the exception today. Identity was tied to the concrete experience of an empirical locality. The identification of the space found its expression in the identity of the people who filled this place with life. The fundamental problem with this is the fact that societation through media and the computer has become part of the normal equipment of society. But how is society and, above all, local (usually meaning urban) community still possible at all under the conditions of virtualization of social structures? This question is the framework for my remarks on the function and purpose of RegioWikis and CityBlogs as media in the formation of space-related identity. 


\section{Who Still Talks of Web 2.0? Web-Based Social Communities and their Function for Individuals}

The so-called Web 2.0 technologies (for an overview Hildebrand \& Hofmann, 2006) have opened up new opportunities for intercommunication, the formation of groups, cooperative production of content, formation of a public and the directing of attention, managing and development of information and knowledge, and for presenting oneself. By now, the cooperative development of knowledge with simultaneous supply and assessment of content have become widespread and accepted to a significant extent, so that there is already talk of the new era of "Wikinomics" (Tapscott \& Williams, 2007). Overall, it can be said that a new cultural practice of knowledge generation has formed that is based on intensive use of networks (Barabási, 2003). At its core this is concerned with the means and methods of how contents are produced and consumed based on the network. Static Web pages are more and more being replaced by interactive wikis or blogs in which the readers themselves become producers and can modify the contents of a Web page by themselves adding information (Alphonso \& Pahl, 2004; Ebersbach et al., 2008; Huber, 2008; Stegbauer \& Jäckel 2008). In other words the consumers participate in the creation and presentation of the contents. The roles of producer and recipient are falling apart, and entirely new worlds of knowledge and areas of identification are arising. The passive end-user is turning into the participating user (Streif, 2006) or "prosumer" (Toffler, 1980) who informs and voluntarily compiles contents and puts them into the relevant wiki or blog.

It should not be ignored that " 2.0 " is a candidate symbol for the beginning 21 st century, an abbreviation that encapsulates the interplay between technological change and the needs of society. In this sense, "Web 2.0 " is also a social construct, an expression of an expectant attitude with a belief in the future (Maaß \& Pietsch, 2007). The subtext conveyed by this aims, in line with the workings of the network, at including in it not only hypertexts but also contents, places, people and events - and so to contribute ultimately to the formation of identity. The symbol " 2.0 " indicates above all the need for a quantum leap in the adoption of reality that makes use of the new continually developing technologies (AJAX, i.e. Asynchronous Javascript And XML, Mashups, RSS, i.e. Really Simple Syndication). The "secret media revolution" (Möller, 2006) comes from the fact that wikis and blogs permit text to be edited without prior registration and without knowledge of the details of HTML. This gives a first hint of why RegioWikis and CityBlogs in conjunction with regions and urban areas and their associated identification processes arouse so much interest. In pluralist societies, communities of like-minded people are increasingly also artificial products. In Web 2.0 it is therefore more a case of also establishing information communities on information platforms, i.e. creating identity participatively. RegioWikis and CityBlogs are platforms that lead to a dominant symbolization of a region and finally to a consciousness related to the regions, and experts in local and regional matters react to each other and this creates an emergent agenda with a regional content. This way, the collaborative information space created by these network media becomes a collective identity space.

RegioWikis and CityBlogs can therefore be viewed as examples of a new form of knowledge that can be dealt with through the media. The distributed digital information spaces that arise from this can readily be analyzed in the context of an extended concept of space with questions from the social and regional sciences. Here the main point is to ask how localityrelated identity is also created in communities of experts through collective (or connective) intelligence (Levy, 1997; de Kerckhove, 2001). 


\section{Regional and Local Identity in the Context of Globalization}

The appearance of dialects, so-called "regiolects" that for decades were despised or considered comical, is an indicator for the "return of the regional" (Lindner, 1994). "If dialect is making a comeback now, that must surely be related to globalization. The world in which we live has become incalculably huge and with a poverty of differences [...]. Many people long for a smaller world in which they can find their way, that gives them something like a homeland (Heimat). We identify less with the state than with the smaller units, the regions that we really know" (Stolz, 2008). This indication should suffice to make it clear that regionalization is emerging as the antithesis to globalization and its associated homogenization. Further strategies of adaptation that cannot be pursued in more detail here are, for example, the world-wide CittaSlow movement and the adaptation of company Web sites in the context of localized communications strategies of multinational companies.

Regions are gaining in significance as the antithesis in scale to the global world of knowledge and the economy. Continuous unpredictable change and the associated adaptation activities are a characteristic of a regional system. A region consists simply of the sum of these adaptation activities in the processes of social change. Against this background, regional science research examines the construction process and the way regional identity functions as a form of adaptation to change. The guiding questions are therefore: What are the effects of the new Web 2.0 technologies on the self-definition of towns and regions? What contents are distributed there and with what consequences? What connection is there between the forms of operation of everyday regionalization of social actors ("regional consciousness") and "official" self-definition of regions ("regional identity")? In terms of method we are here in the area of a multi-level analysis. Here we distinguish between firstly the cognitive level (consciousness of region, distinctiveness from other regions), secondly the affective level (extent of the bond of feeling as the basis for a collective consciousness, demarcation from other forms of identity), and thirdly the instrumental level (potential for mobilizing regional identity for collective actions with political, social and economic goals).

Regions are particular spaces in a medium-scale level. In this context, spaces are understood as social constructs with a structure of meaning, i.e. projected areas for territorial, legal, economic, technical, tourist or other processes that create identities. In this sense, space, region and identity form an inseparable triad that guides actions. Regions are also constructs and therefore not self-evident until there are descriptions and stories about places (narratives) in addition to the availability of symbolic representations; a new form of social reality emerge, that can give rise to identities. "Regional identity" is thus an abstraction that can be called on for understanding processes between social actors and institutionalization processes (Paasi, 2001). However, despite plenty of appearances in research the term is not yet precisely delineated. For example, the terms "regional consciousness", "regional culture" or "regional mentality" are used synonymously. But overall, the term "regional identity" usually has a positive connotation, as it suggests an integrating factor of community formation - and the following is concerned with just this aspect.

What roles do new media play in this? In the area of intercultural comparative migration research or in discourse about transculturality (e.g. Hipfl, 2004) the relationship between media and identity have already been exhaustively dealt with. However, the "identity spaces" and media-brokered communities (e.g. Hipfl \& Hug, 2006) that this examines repeatedly bring community-forming categories such as national identity and body-related 
identity to the fore. Making regional identity-forming processes explicitly a subject of discussion has not yet occurred in the discussions mentioned.

\section{Examples for RegioWikis and CityBlogs from Germany}

What is relatively new is the discourse about "urban narratives" in the area of urbansociology research, that shows that local identities are generated and stabilized by (collective) narratives. These narratives occur in the medium of RegioWikis and CityBlogs. Wikis do not exist solely in the form of the free encyclopedia Wikipedia. There is also the subform of RegioWikis, i.e. wikis with a thematic specialization on information related to specific regions. These can relate locally to a town or district of a town (CityWikis) or their scope can be the medium-scale level of an entire region (RegioWikis). RegioWikis are complementary to the general information in encyclopedia projects. The CityWiki of Karlsruhe (http:/ / ka.stadtwiki.net) is, for example the largest free CityWiki in the world. It is conceived as an information portal for the city of Karlsruhe and its surroundings (administrative district of Karlsruhe). The Karlsruhe CityWiki contains information on all subjects that have a connection to Karlsruhe. It provides detailed and interlinked information about geography, nature, history, politics, religion, education, culture, social matters, sport, economy and transport. The open-source idea has a new manifestation in the form of CityWikis and RegioWikis. The Karslruhe CityWiki is implemented by a "Society for the promotion of free regional knowledge", i.e. by a registered association. This also indicates the high aspirations of such a project. Accordingly this form of wiki has in principle two functions: on the one hand the pooling of information and formation of categories, and on the other hand the creation of relationships to the locality and current events. This can also mean that, for example, local customs (Fig. 1) appear in the media and so become "cultivated". The question in this context is to what extent this form of presenting information represents a contribution to the constitution of local or regional identity.

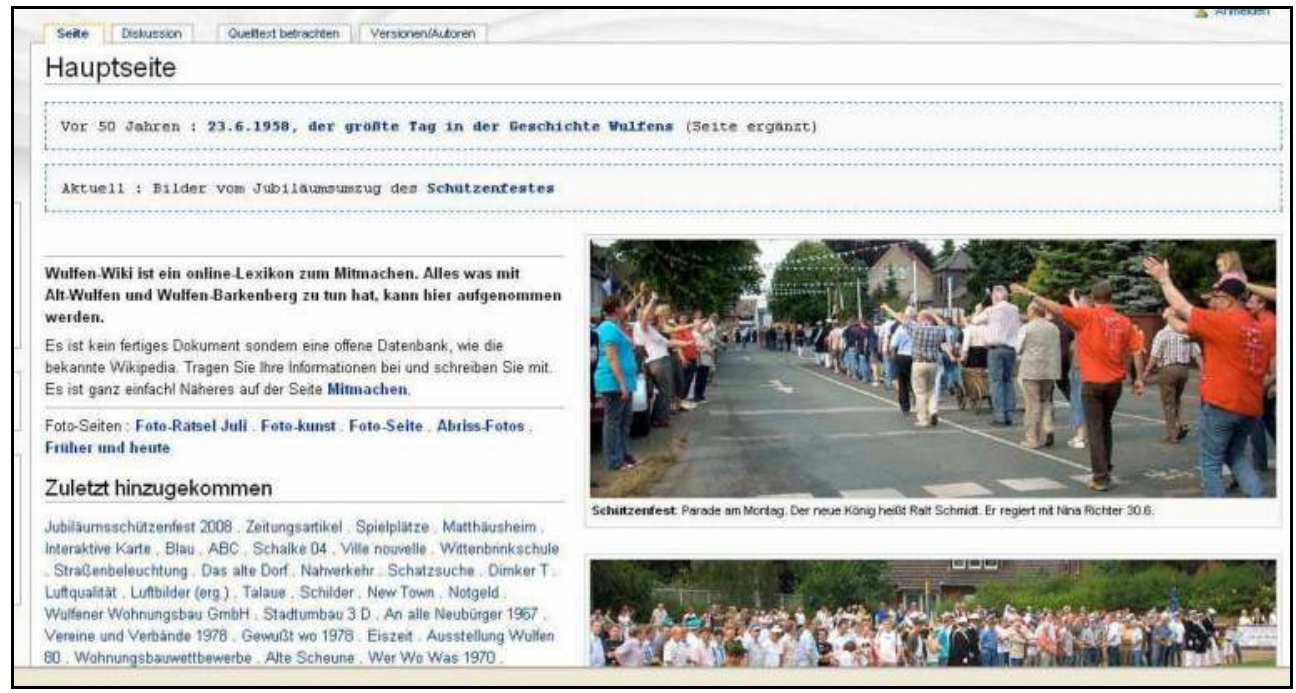

Fig. 1. Preserving customs in a CityWiki (here: shooting match Parade) 
By now there is a multiplicity of wikis and blogs with a clear link to a locality. This has even been the occasion for the formation of the European RegioWiki Society (http://regiowiki.eu/Community_portal) to represent their interests at European level. Figure 2 gives an overview of this.

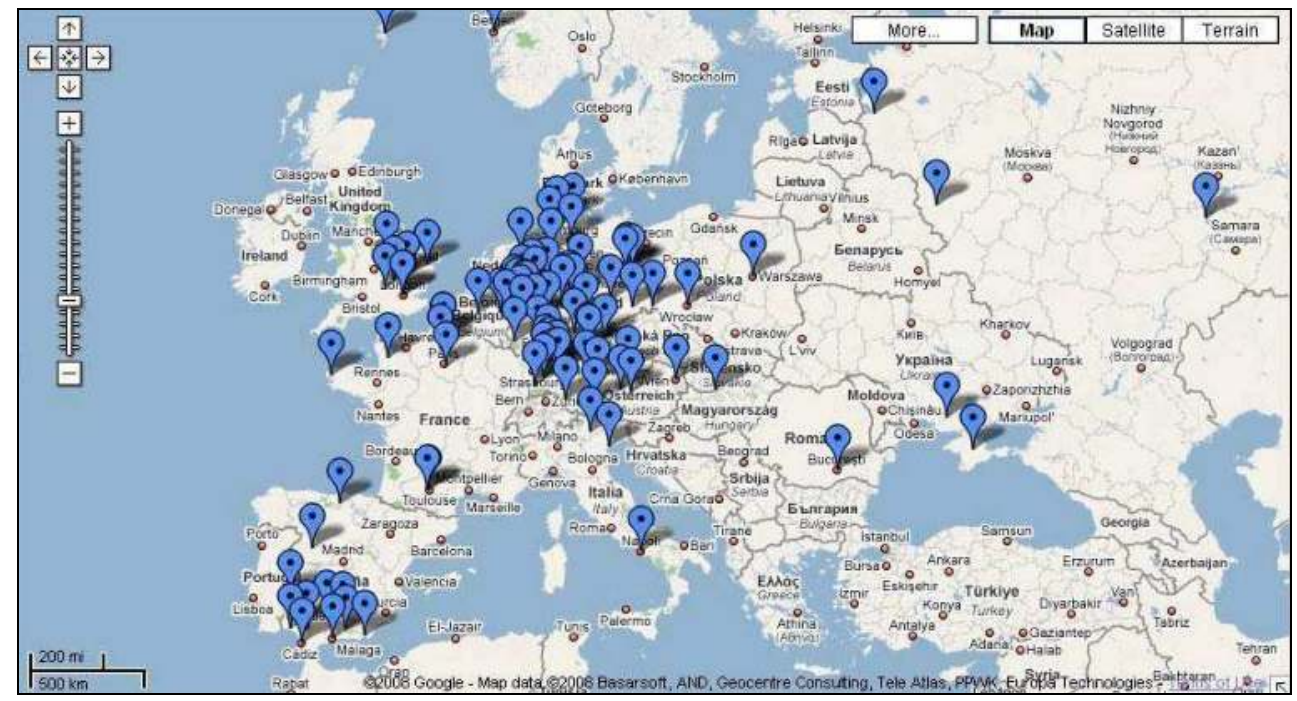

Fig. 2. RegioWikis in Europe (as of 2008)

\section{Results of the Analysis: Web 2.0 Contributes to Identification}

We present here the results of a pilot study on RegioWikis and CityBlogs, obtained in the context of an online study. Further research in this area is taking place at Furtwangen University in the research area "Sociology of Digital Media". As this research area is still being built up, we must here refer to future publications. As an example, RegioWikis ( $n=10)$ and CityBlogs $(n=28)$ were analyzed in summer 2008. The bloggers participating in the examined samples received an online questionnaire on the organizational and content aspects of their RegioWikis or CityBlogs (in the following these terms are subsumed into "new net media"). This made use of the Open-Source survey tool Limesurvey, that is based on PHP and MySQL.

Overall it becomes clear that blogging related to a locality represents a purely private matter. $95 \%$ of the questioned bloggers in the age range 28 to 58 years pursue this form of knowledge generation as a hobby. However, they invest a relatively large amount of time in this. Almost half of the bloggers concerned (46\%) work on their own project between 5 and 10 hours per week. On average 300 readers per day look at the blogs to inform themselves about local events. The bloggers measure the visitor numbers by using server-side statistics (28\%), Google Analytics (31\%), statistics functions integrated in the blogscript, and with external counters, e.g. Blogcounter (21\%). All values are based on multiple selection.

CityBlogs are exceedingly well networked. This is clear from two levels: Firstly the CityBloggers care a great deal about their own readers. A good $30 \%$ of the bloggers read the 
comments and make them visible, 55\% also publish critical comments without further editing and $72 \%$ answer questions from their readers. This intensive involvement of the readers leads overall to a stable form of an online community. The readers of the CityBlogs are thus a part of the production of information by actively providing comments. $10 \%$ comment on the contributions "very often", $20 \%$ comment "often" or "occasionally". All in all, one reader in three sees himself as a kind of active "co-author". This interplay between the authors and the co-authors is for many the attraction of the new net media. Secondly, the CityBloggers are concerned to network their blog actively with others. They do this, for example, by means of blogrolls $(58 \%)$ or by linking to other articles. Almost $20 \%$ also actively send their own contributions to news portals. Most CityBloggers are thus not only producers of information but also consumers. Around $65 \%$ also read other blogs on related topics to provide themselves with locality-related information. Summarizing the questioning of the producers, it becomes clear that CityBloggers have set themselves a timeconsuming activity and are fully aware of their informational responsibility.

The counterpart to this is the perspective of the readers who were also questioned in this study ( $n=200$, with $67 \%$ men and $33 \%$ women). The considerable linking among the CityBlogs in the so-called blogosphere is also demonstrated by the fact that nearly $40 \%$ of readers found their local CityBlog from links on other web sites. $30 \%$ of the readers came to the page in question through recommendations from friends and acquaintances. The remainder found the CityBlog by using search engines, special blog search engines or via an RSS feed. CityBlogs are not merely something in the margins. This is expressed in the figures that a good half of readers (53\%) visit their CityBlog in the Internet at least once per day, or even several times. A particularly interesting question was why such a format is used in the first place. Implicit in the answers is the special nature of the construction of local identity through the new net media. Almost $73 \%$ of the readers (these are all "top-box values", i.e. the number of those who "agree" or "entirely agree" with a statement) find "their" blog entertaining and interesting; 64\% would like to have news from the region or locality via this medium. And in any case 39\% look in the blog for special locality-related information that they do not find in the classical media. The relationship to a locality also plays a part when the readers do not live in the place to which the blog relates. It turns out that every fifth reader reads the blog because he used to live there or spent his childhood there. A CityBlog thus makes a virtual form of local identity possible.

In contrast to the bloggers, the readers spend much less time on the net. Only $5 \%$ read for 2 to 4 hours per day, but $20 \%$ read 1 to 2 hours per day. However, by a reverse argument this shows one of the essential functions of the CityBlog: They are excellent instruments of information reduction, information contextualizing and target-group-specific editing of information about a locality. Overall, the readers are indeed very satisfied with the information provided. For three quarters of them (76\%) the CityBlog provides a "true" picture of "their" region. A similar number (78\%) thinks that the reporting in the new net media is as it "really is" in the region or city. For $84 \%$ of readers the contents of the new net media even give them a (new) attitude towards life in the locality.

The new net media count as "innovation generators". $81 \%$ of the readers consider that it was only by this means that they have become aware of new matters in the region and $86 \%$ find in their CityBlog information or news that they do not find, or do not find in this form, in other media. This character of exclusiveness that is present in the "sovereignty of information" in the locality is surely the most important unique characteristic. $85 \%$ of the 
readers even think that the contributions in the new net media are above all characterized by being more authentic than the news from newspapers, radio and television. They consistently consider these reports to be more trustworthy. This can also be seen in that only $13 \%$ of the readers believe that their region is presented in the new net media "more positively" than it really is.

This overall very positive view of the readers expressed in the quantitative parameters must be contrasted with the qualitative self-descriptions of the suppliers of information. The motivation of the CityBloggers will become clear in the following self descriptions. The quotations are from the open qualitative interviews with the bloggers and readers. It consists generally of casting a "news-like" and yet "subjective" eye over the region, which will fill a niche in the offering from the media and thereby make a contribution to the freedom of opinion. In doing this the bloggers value the interactive opportunity for receiving the resonance of the readers. This property can be understood as the feedback channel ability of the medium in the sense of Bertolt Brecht's radio theory, see Brecht (2004). They want to provide a navigation aid through the "urban jungle" and help the town towards an "extended historical memory". The value and the range that arises on this basis can be represented in a little typology.

Firstly there is the explicit wish to offer local information. In other words this concerns "what is happening in the town, in all its aspects". Locality-related information is at the forefront in this: local politics, local culture etc. The contents of the new net media provide, in this context, a "good overview over local reporting" indeed because they (critically) encompass the reporting of the classical media. Most bloggers have in this a very broad aspiration. "It's really a matter of documenting what's happening in the town" according to one of the bloggers questioned. A symbiosis is thus formed from the practice of the town and the practice of blogging. This is clear in the following comment: "There is always enough in the town that can upset me. But there are also always enough things that I can mention positively. That makes it interesting."

Secondly the new net media form an information corrective for the interested public. Against the background of the loss of trust in the old media, a CityBlog can, in the ideal case, serve as a corrective and relative the information from other media. Or it simply creates visibility where otherwise nobody looks: "The place is left in the cold by the press, so I supply the information", according to one blogger. In CityBlogs information is provided that is "otherwise not made known to the public anywhere". This encourages the bloggers to continue with their singular projects. "I blog about what's going on in the region because the other media just don't report on it; they simply find it not worth mentioning!" In this way the regional peculiarities (customs, traditions) that are representative for the identity of a town, but otherwise make almost no appearance in reporting, are presented in a more prominent and pointed manner and so are brought "into people's minds".

Thirdly CityBloggers use an emotionalized reporting style that sets them apart from the usual standard journalism. One study participant commented "I come to grips with my city - not on a completely objective level but from the belly, spontaneously and fast". A regional consciousness can arise from this basis. "I identify myself simply with my home town, as do my readers. That animates me to compile reports about it. The only important thing in that is the local connection", according to another blogger.

From this comes fourthly the discursive potential of the new net media. As this blogger explains, it is possible to initiate a public exchange of opinions by publicizing the locality- 
related material. "It's not only my personal interests, I also report because there's a great need for discussion about many subjects." The areas of discourse are definitely driven by need, i.e. the bloggers react to the demand from their readers. One of the study participants explains: "I consistently direct my editorial work to the interests of my readers. I determine their interests by means of search engines" (keyword targeting).

Some of the CityBlogs examined are fifthly characterized by an explicit intervention in local planning contexts. In this connection, one blogger mentions that for him it is a matter of "reporting on building activity which is having extreme consequences for this district". Another dedicatedly documented the local election campaign with "sometimes electorally decisive conveying of opinion". Additionally, intervention at certain points in town planning can also be demonstrated, such as in the criticisms of a cinema entrance without provision for the disabled, or the discussion about opening times of a swimming bath.

\section{Digression: CityBloggers in the Tradition of the Town Clerk}

The town clerk of the middle ages and early modern times ("notarius civitatis") was among the most powerful men of the town. He not only documented the happenings of the town, but he was also a jurist, an adviser and a politician. As a rule his post was for life, which further underlines the significance of the town clerk's activities. His job requirements show clear parallels to the self-descriptions of the CityBloggers. The town clerk needed a full overview of all events and happenings in the town. He helped to correct errors, drew attention to shortcomings in politics and administration, recognized the need for regulations and made suggestions for improvement. The town clerk was thus an important partner in the planning of the town's development, which related both to personnel policy and to actual town-planning activities. The institution of the formal town clerk lives on in the age of Web 2.0 in the form of the networked and therefore informally operating CityBloggers.

Another example: the best known chronicler poet of Brazil, Gregório de Matos (1636-1695), can certainly be regarded as a distant forerunner of today's CityBloggers. In the combination of social chronicle and defamatory poem, he criticized the corrupt, ambitious, unscrupulous and morally rotten society of his time, earning the nickname boca do inferno among the inhabitants of Salvador da Bahia (then the capital of Brazil). Gregório de Matos was - like a modern Blogger - involved in the politics of the day. His direct language and great subjectivity resulted in a commentary on the times and history of the morals of the time that are unparalleled to this day. The numerous filhos da folha, whom he criticized in his defamatory verses, managed to expel him from the land at the end of his life.

\section{Conclusion: Further Research on RegioWikis and CityBlogs at Larger Scale Needed}

Castells (2002) has already criticized the fact that in the networked information society, cultural codes and values are increasingly influenced by technical abilities. Can we therefore expect that regional and local identities will soon be only what Web pages, PDAs, mobile telephones etc. are able to present? How is our perception changing, our concept of beauty and originality, under the conditions of media culture and digitized aesthetics? Is a "culture of real virtuality" arising with this, in which we are dealing, not with real spaces, towns and districts, but only with symbolic worlds of experience in which virtuality takes on the 
character of living spaces that are actually present (and thereby influence behavior) as in the fantasy novel "Otherland"?

Although the new net media dealt with here are driving this development forwards, RegioWikis and CityBlogs and the associated "digital production communities" (Tepe \& Hepp 2008) can nevertheless be scored positively. If we pursue the assertions of the users, these net media offer an entirely new type of information: Neighborly, individualized and personalized information. They thereby fulfil the longing for authenticity in a hyperreal world of simulations (Baudrillard). From the reader's viewpoint, the new net media presented here have three basic functions, that will be briefly mentioned in closing, in order to show that supply and demand are well matched. The critic function is usually mentioned first. For the readers the new net media have the potential to go over local scandals with a "sharp tongue" (like Gregório de Matos) and really get to the point. The foundation for this is the permanent creation of relationships to people and places. "What you don't know so well, suddenly acquires a face" says one reader. From the subjective nature of the reporting, a humanness and authenticity are constructed, that are separate from the mainstream in a beneficial way. "I read a lot of blogs related to places because people in them come over as people. That is something fundamentally different from the formally organized news business", is the comment of a reader on this basic function.

A problem with this is the scaling of local or regional identity. The type of information described above necessarily has to refer to ever smaller units of space in order to achieve its full effect. On the one hand there are indeed CityBlogs that have the aim of representing an entire town or metropolis. On the other hand there are also, ever more frequently, projects for extremely small spaces such as a VillageWiki. These projects live even more on the fact that many user groups with their differing cultures participate in them and subsequently "fractal communities" (Nahrada, 2007) arise. This ends in a paradox, since the formation of collective identities does not harmonize well with extreme individualization.

In closing, let us venture to take a look forwards: Future research on the locality-related use of new net media must meet the following criteria. Firstly it must be empirically based. The selection of samples from the large number of projects must be guided by theory. In the present case, only an arbitrary random selection could be made, in order to gain a first impression of the field to be examined. This also applies for the selection in accordance with criteria of regional disparity and along an axis of greater and lesser urbanity. Secondly the cross-section analyses indicated here need to be followed in future by longitudinal studies, that look at the development of the topics and user behavior over a period of at least a year. Thirdly the research on RegioWikis and CityBlogs should be carried out cross-culturally. On the intercultural scale valuable insights can be expected into demand and supply of regional identification processes.

People concentrate in the "space of places", and information in the "space of flows" (Castells, 2002). The spaces interpenetrate each other, as is shown by the examples of RegioWikis and CityBlogs. People who are in the space of places use their information power in the space of flows in order to spread what is worth knowing about the space of places. They thereby make possible a virtual "experiencing" of empirical places (in contrast to, for example, Second Life). If regions can be defined as the sum of the activities of adaptation to the processes of social change, the new net media are intervening profoundly in these processes. RegioWikis and CityWikis are examples of media-induced and virtual discourses that are typical for the information and knowledge-based society. 


\section{References}

Alphonso, D. \& Pahl, Kai (2004). Blogs! Fünfzehn Blogger über Text und Form im Internet und warum sie das Netz übernehmen wollen, Berlin

Barabási, A.-L. (2003). Linked - How Everything is Connected to Everything Else and What It Means for Business Science, and Everyday Life, London

Bell, D. (1979). Die nachindustrielle Gesellschaft [The Post-Industrial Society], Hamburg

Brecht, B. (2004). Radio - eine vorsintflutliche Erfindung? Vorschläge für den Intendanten des Rundfunks. In: Helmes, G. \& Köster, W., Texte zur Medientheorie, Stuttgart

Castells, M. (2002). Das Informationszeitalter. Band 3: Die Netzwerkgesellschaft. [The Rise of the Network Society], Opladen.

De Kerckhove, D. (2001). The Architecture of Intelligence, Basel

Drucker, P.F. (1999). Die Zukunft bewältigen, Düsseldorf

Ebersbach, A.; Glaser, M. \& Heigl, R. (2008). Social Web, Konstanz

Hildebrand, K. \& Hofmann, J. (2006). Social Software, Heidelberg

Hipfl, B. (2004). Medien als Konstrukteure (trans-)nationaler Identitätsräume. In: Ident. Nation, Körper und Geschlecht in den Medien. Eine Topographie, Bielefeld, 53-59

Hipfl, B. \& Hug, T. (2006). Media Communities, Münster

Hitzler, R. \& Honer, A. (1989). Bastelexistenz. Über subjektive Konsequenzen der Individualisierung. In: Beck, U. \& Beck-Gernsheim, E., Riskante Freiheiten. Individualisierung in modernen Gesellschaften, Frankfurt

Huber, M. (2008). Kommunikation im Web 2.0, Konstanz

Lévy, P. (1997). Die kollektive Intelligenz: für eine Anthropologie des Cybersp., Mannheim

Lindner, R. (1994). Die Wiederkehr des Regionalen. Über neue Formen kult. Id., Frankfurt

Maaß, C. \& Pietsch, G. (2007). Web 2.0 als Mythos, Symbol und Erwartung. Diskussion. Nr. 408, Fakultät für Wirtschaftswissenschaften der FernUniversität Hagen

Möller, E. (2006). Die heimliche Medienrevolution. Wie Weblog, Wikis und freie Software die Welt verändern, Hannover

Nahrada, F. (2007). Das Dorfwiki als fraktale Commnity - ein vorläufig wenig erfolgreicher, aber dennoch weitergeführter Versuch. In: Kommunikation \& Gesellschaft

Paasi, A. (2001). Bounded Spaces in the Mobile World. Deconstructing "Regional Identity". In: Tijdschrift voor economische en social geografie, 93, 137-148

Sennett, R. (2000). Der flexible Mensch. Die Kultur des neuen Kapitalismus [The Corrosion of Character], Berlin

Stegbauer, C. \& Jäckel, M. (2008). Social Software. Formen der Kooperation in computerbasierten Netzwerken, Wiesbaden

Stolz, M. (2008). Die neue Dialektik. Warum sich die Deutschen nicht mehr für ihre Mundarten schämen. In: Zeit Magazin Leben, 26

Streif, A. (2006). Wiki - Zusammenarbeit im Netz, Norderstedt

Tapscott, D. \& Williams, A.D. (2007). Wikinomics. How Mass Collaboration Changes Everything, London

Tepe, D. \& Hepp, A. (2008). Digitale Produktionsgemeinschaften. Die Open-SourceBewegung zwischen kooperativer Softwareherstellung und deterritorialer politischer Verg. In: Stegbauer \& Jäckel, Social Software, Wiesbaden, 27-48

Toffler, A. (1980). Die dritte Welle. Zukunftschancen und Perspektiven für das 21. Jahrhundert, München

Wolff, P. (2007). Die Macht der Blogs. Chancen, Risiken, rechtliche Grundlagen, Frechen 


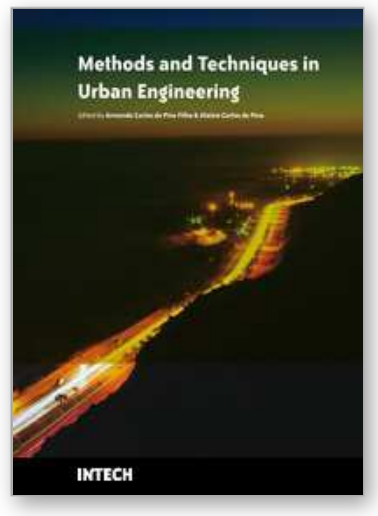

\author{
Methods and Techniques in Urban Engineering \\ Edited by Armando Carlos de Pina Filho and Aloisio Carlos de Pina
}

ISBN 978-953-307-096-4

Hard cover, 262 pages

Publisher InTech

Published online 01, May, 2010

Published in print edition May, 2010

A series of urban problems such as dwelling deficit, infrastructure problems, inefficient services, environmental pollution, etc. can be observed in many countries. Urban Engineering searches solutions for these problems using a conjoined system of planning, management and technology. A great deal of research is devoted to application of instruments, methodologies and tools for monitoring and acquisition of data, based on the factual experience and computational modeling. The objective of the book was to present works related to urban automation, geographic information systems (GIS), analysis, monitoring and management of urban noise, floods and transports, information technology applied to the cities, tools for urban simulation, social monitoring and control of urban policies, sustainability, etc., demonstrating methods and techniques applied in Urban Engineering. Considering all the interesting information presented, the book can offer some aid in creating new research, as well as incite the interest of people for this area of study, since Urban Engineering is fundamental for city development.

\title{
How to reference
}

In order to correctly reference this scholarly work, feel free to copy and paste the following:

Stefan Selke (2010). Urban Engineering 2.0 - Medial Construction of Regional and Local Identification with RegioWikis and CityBlogs, Methods and Techniques in Urban Engineering, Armando Carlos de Pina Filho and Aloisio Carlos de Pina (Ed.), ISBN: 978-953-307-096-4, InTech, Available from:

http://www.intechopen.com/books/methods-and-techniques-in-urban-engineering/urban-engineering-2-0medial-construction-of-regional-and-local-identification-with-regiowikis-and-c

\section{INTECH}

open science | open minds

\section{InTech Europe}

University Campus STeP Ri

Slavka Krautzeka 83/A

51000 Rijeka, Croatia

Phone: +385 (51) 770447

Fax: +385 (51) 686166

www.intechopen.com

\section{InTech China}

Unit 405, Office Block, Hotel Equatorial Shanghai

No.65, Yan An Road (West), Shanghai, 200040, China 中国上海市延安西路65号上海国际贵都大饭店办公楼 405 单元

Phone: $+86-21-62489820$

Fax: +86-21-62489821 
(C) 2010 The Author(s). Licensee IntechOpen. This chapter is distributed under the terms of the Creative Commons Attribution-NonCommercialShareAlike-3.0 License, which permits use, distribution and reproduction for non-commercial purposes, provided the original is properly cited and derivative works building on this content are distributed under the same license. 